\title{
Perubahan Identitas Musik Pop pada Versi Cover di Indonesia
}

\author{
${ }^{1}$ Dessyratna Putry, ${ }^{2}$ Aquarini Priyatna, ${ }^{3}$ Lina Meilinawati Rahayu \\ ${ }_{1,2,3}$ Prodi S2 Kajian Budaya Universitas Padjadjaran \\ dessy15002@mail.unpad.ac.id
}

\begin{abstract}
Abstrak
Penelitian ini membahas perubahan identitas musik pop Indonesia yang dipublikasikan melalui situs YouTube. Lagu yang diteliti adalah Akad dari Payung Teduh yang di-cover oleh Mas Paijo dan Pamit dari Tulus yang di-cover oleh Sintesa Vocal Play. Penelitian ini menggunakan pendekatan transit dan transisi dengan kajian tekstual dan kontekstual pada identitas kedua lagu tersebut. Tujuan dari penelitian ini ialah untuk menemukan bagaimana identitas musik (lagu) beserta musisinya mengalami perubahan; dari versi orisinal menjadi versi cover. Dalam penelitian ini dipahami bahwa versi cover merupakan bentuk pembaruan musikal. Penjelasan mengenai perubahan identitas dalam kedua versi ini dibahas pada dua substansi. Pertama, narasi tentang peran teknologi dalam pembaruan musikal; kedua, uraian tentang perubahan identitas dalam narasi musikal yang meliputi lirik lagu, format lagu, instrumentasi, video musik berserta musisinya. Dengan demikian, perubahan identitas yang ditelaah dalam penelitian ini meliputi dua versi lagu: orisinal dan cover dengan dua narasi yang berbeda.
\end{abstract}

Kata kunci: identitas, orisinal, cover, lagu

\begin{abstract}
This research discusses changing identity of Indonesian pop music's that was published on YouTube. Spesifically, there are two song's (consist of original version and cover version) discussed here: firstly, Akad original version by Payung Teduh and cover version by Mas Paijo; secondly, Pamit original version by Tulus and cover version by Sintesa Vocal Play. This research applies transit and transition approach in which the signs in textual and contextual data are examined in their identity. The aim of this research is to find out how music and musician identity are represented in their song's include in cover version. This research shows that cover version is defined as music renewal of the whole music and musician narration. Description about changing identity in both version (original and cover) was observed in two subject. Firstly, narration about technology involvement in music renewal and secondly, description about changing identity in musical narration (including in song lyrics, song forms, instrumentation, music video and the musician). It can also be said that changing identity refers to both version (original and cover) with two different descriptions.
\end{abstract}

Keywords: identity, original, cover, song

\section{Pendahuluan}

Penelitian ini membicarakan isu perubahan identitas lagu-lagu pop Indonesia pada versi cover yang beredar melalui situs YouTube di tahun 2016-2017. Versi cover adalah suatu versi lain dari lagu yang sebelumnya sudah ada, sudah direkam, dan 
dipublikasikan oleh seorang penyanyi maupun band yang telah dikenal luas (Plasketes, 2010: 226). Dua lagu pop Indonesia yang dianalisis dalam tulisan ini, yaitu: Akad oleh Payung Teduh beserta versi cover-nya oleh Mas Paijo dan Pamit oleh Tulus beserta versi cover-nya oleh Sintesa Vocal Play featuring Anandito. Alasan pemilihan kedua lagu tersebut ialah adanya kesamaan genre musik pada versi orisinalnya dan adanya isu perubahan identitas yang signifikan pada versi cover-nya.

Dalam sejarah pengcoveran lagu, sebagaimana dibahas pada Music Cultures in the United States (Wolfe, 2005: 349-350) disebutkan bahwa versi cover mulai muncul di Amerika oleh musisi kulit putih pada lagu-lagu musisi kulit hitam. Salah satunya dalam lagu Sh-Boom karya Crew Cuts (musisi kulit hitam) yang awalnya bergenre blues kemudian berubah menjadi genre pop oleh musisi kulit puith. Lagu Sh-Boom versi orisinal dipublikasikan pada 19 Juni 1954 dan versi cover-nya muncul pada 3 Juli 1954. Pada 10 Juli 1954 lagu Sh-Boom masuk dalam daftar lagu-lagu pop hingga beberapa tahun kemudian versi cover ini direkam dan dipublikasikan sebagai lagu bergenre pop oleh musisi kulit putih. Pada masa itu sudah menjadi hal yang lumrah ketika lagu-lagu musisi kulit hitam di-cover oleh musisi kulit putih. Sindrom cover version saat itu bukan saja disebabkan oleh permasalahan rasisme, melainkan juga karena persaingan bisnis di antara label rekaman keduanya.

Sementara itu, sejarah versi cover di Indonesia ditulis oleh Wallach (2008: 214216) dalam Modern Noise, Fluid Genres: Popular Music in Indonesia, 1997-2001 yang menjelaskan bahwa versi cover mulai dikenal di Jakarta melalui pementasan-pementasan seni (pensi) di sekolah sekitar akhir tahun 1990-an. Dalam kurun waktu tersebut mulai bermunculan band-band lokal yang menciptakan versi cover pada lagu-lagu Barat, contohnya: Band Tor yang meng-cover lagu-lagu Jimi Hendrix, Rastafari meng-cover lagu-lagu Bob Marley kemudian T-Five meng-cover lagu-lagu Korn and Limp Bizkit; saat itu versi cover diciptakan bukan hanya dari segi komposisi musiknya saja melainkan juga pada aksi panggungnya. Hingga kini versi cover semakin berkembang dan marak diunggah melalui situs YouTube.

Fenomena cover version yang tidak terlepas dari penggunaan teknologi ini mengantarkan pada pembahasan bagaimana teknologi dan seni (musik) saling terkait. Hal ini diuraikan oleh Yangni (2016: 4-5) bahwa kaitan antara seni dan teknologi sepanjang sejarah relasi keduanya tampak terpisah, namun secara esensial keduanya menyatu. Merunut mundur pada zaman Yunani, tidak ada pemisahan sama sekali antara seni dan teknologi. Keduanya sama dan satu dilakukan oleh tiap individu dalam masyarakat untuk mendukung kehidupan. Kemudian di masa selanjutnya, zaman modern mengenal pemisahan itu dengan menggolongkan teknologi pada mesin dan kepentingan produksi. Hal ini mengakibatkan seni sering kali menjadi oposisi sekaligus mengkritisi teknologi (mesin produksi, sistem kapital, dan lain sebagainya) menjelma mesin yang meringkas hubungan manusia sesungguhnya. Namun demikian, kini tampaknya teknologi tak lagi soal produksi, melainkan telah beralih pada reproduksi. Teknologi kini meningkatkan nilai-nilai estetik ataupun gaya tertentu; sebuah pergerakan estetik yang mendatangkan penghasilan. Di sisi lain, peran teknologi mengantar pada telaah budaya populer dalam identitas musik. 
Teknologi yang digunakan sepanjang proses bermusik seseorang secara tidak langsung menunjukkan identitasnya; pengalaman bermusik didukung pemilihan teknologi yang digunakan, menghasilkan sebuah karya yang tidak terlepas dari identitas seseorang sebagai musisi. Frith (2004: 109) menerangkan bahwa pengalaman bermusik yang dimiliki individu maupun kelompok berkontribusi terhadap pembentukan identitas diri dan karya musik yang diciptakan; seperti pernyataan Koskof sebagaimana dikutip oleh Gustina (2010: 90) bahwa musik dapat dipahami sebagai suatu penanda atas identitas seseorang maupun kelompok untuk mendeskripsikan diri mereka terhadap lingkungan dan orang lain; begitu pula sebaliknya, sebagai bentuk pemahaman orang lain dalam mendefinisikan diri mereka. Musik dapat digunakan sebagai atribut untuk menunjukkan perbedaan antara individu atau kelompok yang satu dengan lainnya.

\section{Metode Penelitian}

Penelitian ini merupakan penelitian deskriptif kualitatif dengan pendekatan teori transit dan transisi Svašek (2012: 2-5); transit ialah pergerakan keberlangsungan suatu objek karya seni maupun budaya yang melintasi batas geografis, rentetan sejarah, sosial dan kultural sekaligus melintasi batasan ruang dan waktu, sedangkan transisi ialah analisis pemaknaan terhadap status dan nilai suatu objek karya seni maupun budaya. Fokus dari teori transit dan transisi ini pada proses perubahan suatu karya seni (musik) menjadi bentuk lain, baik dari segi konten maupun nilai dan pemaknaannya yang direlasikan dengan pemahaman, pengalaman, konteks kesejarahan, maupun kondisi sosial yang melatarbelakangi terjadinya proses perubahan tersebut.

Analisis struktural dilakukan guna mencapai tujuan penelitian ini. Analisis tersebut terdiri dari: pengumpulan data yang dilakukan untuk menentukan dua lagu pop terpilih beserta versi cover-nya yang dipublikasikan antara tahun 2016 hingga 2017 pada situs YouTube; langkah berikutnya dilakukan dengan mengidentifikasi pokok permasalahan berdasarkan kriteria yang digagas oleh Svašek dan didukung data-data dari beragam buku, jurnal, tesis serta penelusuran melalui situs internet untuk memperoleh gambaran yang komprehensif mengenai perubahan identitas lagu-lagu pop pada versi cover; langkah terakhir dilakukan ketika jawaban atas pertanyaan penelitian mulai menunjukkan tanda bahwa pengcoveran berkontribusi terhadap perubahan identitas sebagaimana ditampilkan dalam kedua lagu, maka selanjutnya hal tersebut dideskripsikan hingga memperoleh kesimpulan sebagai hasil akhir; jawaban atas keseluruhan pertanyaan penelitian.

\section{Hasil dan Pembahasan}

\section{Peran Teknologi dalam Pembaruan Musikal}

Dalam penelitian ini, peranan teknologi pada pembaruan musikal ditampakkan melalui hubungan preferensi penonton dan penghasilan yang diperoleh cover creator melalui video yang diunggahnya pada situs YouTube. Menurut penelitian yang dilakukan oleh Litbang Kompas diketahui bahwa perkembangan teknologi digital telah mengubah 
gaya hidup generasi muda, termasuk cara dan kebiasaannya dalam menikmati musik. Kondisi tersebut tergambar dari hasil jajak pendapat Harian Kompas yang diselenggarakan pada Agustus 2015. Sedikitnya ada satu persen dari 734 responden yang berhasil terjaring dalam jajak pendapat ini yang mengaku masih mendengarkan musik melalui perangkat pemutar kaset atau CD. Mayoritas responden kelompok muda lebih terbiasa menikmati musik melalui internet, baik dengan cara mengunduh maupun mendengarkan langsung secara streaming. Tidak kurang dari 62\% dari 734 responden mengaku biasa mengunduh lagu dalam format digital di internet dan sekitar 15\% lainnya mengakses melalui streaming musik pada situs YouTube (https://muda.kompas.id/2016/01/06/layar-jajak-industri-musik-redup-oleh-digital/ diakses pada 1 Mei 2018). Semakin muda usia responden, semakin besar pula kegemaran mereka menikmati musik dalam bentuk digital. Sementara itu, International Federation of Phonographic Industry (IFPI) mencatat bahwa pada tahun 2016 pendapatan industri perekaman musik dalam skala global terdiri dari 50\% pendapatan melalui kanal digital, 34\% penjualan dalam bentuk fisik, $14 \%$ dari hak cipta dan $2 \%$ pendapatan dari penggabungan keseluruhannya (http://www.ifpi.org/global-statistics.php diakses pada 5 Mei 2018).

Unsur komersialisasi direlasikan dengan preferensi para penikmat musik sebagai bentuk selera musik mereka. Jumlah pelanggan dan banyaknya penonton pada kedua lagu versi cover dicatat per 5 Mei 2018 pukul 15.15 WIB. Versi cover lagu Akad oleh Mas Paijo telah ditonton sebanyak 3.312.389 kali dengan jumlah pelanggan sebanyak 70.955 orang dan versi cover lagu Pamit oleh Sintesa Vocal Play featuring Anandito telah ditonton sebanyak 98.257 kali dengan jumlah pelanggan 3.618 orang. Melalui penelusuran pada situs YouTube tampak semakin banyak bermunculan cover creator yang direlasikan dengan jumlah penghasilan yang dapat diperoleh. Edinger menjelaskan bahwa penghasilan melalui video yang diunggah pada YouTube berasal dari AdSense, Patreon, Affiliate links, Merchandise dan Brand ads

(http://www.bbc.co.uk/newsbeat/article/42395224/evan-edinger-the-five-ways-youtubers-make-money diakses pada 18 Desember 2017). Uraian data statistik mengenai pendapatan cover creator telah dicatat melalui media socialblade; sebuah situs daring yang menginformasikan progress dan perkembangan penghasilan content creator pada YouTube dalam bentuk grafik statistik (https://socialblade.com/info diakses pada 11 Mei 2018). Daftar kalkulasi tersebut diuraikan sebagai berikut:

\begin{tabular}{|l|l|l|l|}
\hline $\begin{array}{l}\text { Lagu dalam Versi } \\
\text { Cover }\end{array}$ & $\begin{array}{l}\text { Jumlah } \\
\text { Penonton }\end{array}$ & $\begin{array}{l}\text { Jumlah } \\
\text { Pelanggan }\end{array}$ & $\begin{array}{l}\text { Kalkulasi Pendapatan Cover } \\
\text { Creator per bulan }\end{array}$ \\
\hline Akad oleh Mas Paijo & 3.312 .389 & 70.955 & $\begin{array}{l}\text { \$338 }-\$ 5.4 \mathrm{~K} \text { atau setara dengan } \\
\text { Rp 4.732.000 - Rp 75.600.000 }\end{array}$ \\
\hline $\begin{array}{l}\text { Pamit } \text { oleh Sintesa } \\
\text { Vocal Play }\end{array}$ & 98.257 & 3.618 & $\begin{array}{l}\text { \$373 - \$6K atau setara dengan } \\
\text { Rp 5.222.000 - Rp 84.000.000 }\end{array}$ \\
\hline
\end{tabular}

Sumber: www.socialblade.com

Dengan penghasilan yang diperoleh cover creator melalui video cover yang diunggahnya pada YouTube memunculkan nilai kapital sebagai bagian dari peranan kemajuan teknologi. Baudrillard sebagaimana dikutip oleh Swara (2014: 9-12) menerangkan bahwa penyebaran tanda dalam ruang lingkup sosial masyarakat merupakan 
hasil dari logika kapitalisme global yang mengubah media menjadi mesin tanda yang tidak pernah berhenti memproduksi tanda dengan kecepatan tinggi mengikuti percepatan perputaran modal; dalam kenyataannya, kini masyarakat menjadi semakin konsumtif terhadap informasi semenjak kehadiran new media, yaitu YouTube. Oleh karenanya, dalam tulisan ini, kemajuan teknologi selalu berhubungan dengan pembaruan musikal yang dimunculkan melalui cover version sebagai gambaran realitas sosial masyarakat terhadap kapitalisme. Hal ini secara tidak langsung menandakan bahwa identitas yang berubah tidak terlepas dari kemajuan teknologi yang digunakan.

Peran teknologi dalam pembaruan musikal ditelaah melalui dua lagu. Lagu pertama ialah Akad dari Payung Teduh yang diproduksikan oleh Payung Teduh \& Seraya Creative Studio. Video musik lagu Akad dipublikasikan melalui YouTube pada 4 September 2017 dengan jumlah penonton sebanyak 72.459.016. Lagu Akad merupakan bagian dari album Ruang Tunggu yang dipublikasikan dalam bentuk musik digital melalui Spotify, iTunes, JOOX, Deezer, dan Amazon. Payung Teduh mendirikan label rekaman sendiri dengan menaungi seluruh proses industri, mulai dari penciptaan hingga pemasarannya secara mandiri. Sementara itu, pengcoveran lagu Akad oleh Mas Paijo dipublikasikan melalui situs YouTube pada 7 September 2017 dengan jumlah penonton sebanyak 3.312.389. Mas Paijo adalah seorang cover creator yang mengawali karirnya pada situs YouTube sejak 21 Juli 2017 dengan total video yang ia unggah sebanyak lima belas video dan telah ditonton secara keseluruhan sebanyak 5.457.084 kali sejak ia mengawali karirnya (https://www.youtube.com/channel/UCiQNOegYeCp6rQchOZZG_xw/about diakses pada 5 Mei 2018).

Pembahasan selanjutnya ialah lagu Pamit dari Tulus yang diproduksikan oleh TulusCompany; sebuah label rekaman indie yang didirikan oleh Tulus beserta kakaknya, Riri Muktamar pada tahun 2010 (https://www.situstulus.com/biografi/diakses pada 6 Mei 2018). Lagu Pamit dipublikasikan melalui YouTube pada 27 Februari 2016 dengan jumlah penonton sebanyak 33.206.807 (https://www.youtube.com/watch?v=G2-ZC9NpDBg diakses pada 5 Mei 2018). Lagu ini merupakan bagian dari album Monokrom yang dijual dalam bentuk digital, yaitu pada JOOX, iTunes, Spotify, dan Deezer sejak 26 Februari 2016. Kemajuan teknologi dimanfaatkan oleh TulusCompany dalam menghasilkan karya musik, salah satu contoh pada proses perekaman lagu Pamit. Menurut berita dari website resmi Tulus, diketahui bahwa proses perekaman lagu Pamit beserta penggarapan video musiknya dilakukan di dua lokasi: Bandung-Indonesia dan Praha-Republik Ceko (https://www.situstulus.com/press-release-pamit/ diakses pada 7 Mei 2018).

Sementara itu, pengcoveran lagu Pamit oleh Sintesa Vocal Play yang berkolaborasi dengan Anandito ini dipublikasikan melalui situs YouTube pada 9 April 2016 dengan jumlah penonton sebanyak 98.257. Sintesa Vocal Play merupakan grup musik akapela dari Yogyakarta yang terbentuk sejak tahun 2003 (http://www.sintesavocalplay.com/ diakses pada 7 Mei 2018). Sintesa dikenal sebagai YouTube cover creator sejak 7 Januari 2016 dengan total video cover sebanyak delapan dan total penonton untuk keseluruhan video yang diunggahnya sebanyak 455.615.

Perubahan identitas dalam segi teknologi ini direlasikan dengan unsur kenamaan yang dimiliki Payung Teduh dan Tulus dengan pemasaran karyanya pada ruang yang luas kemudian mengalami perbanyakan melalui versi cover dengan ruang pemasaran jauh 
lebih sempit tetapi masih mendapatkan apresiasi publik. Lagu Akad dengan jumlah penonton sebanyak 72.459.016 pada versi orisinal dan 3.312.389 pada versi cover serta lagu Pamit dengan jumlah penonton sebanyak 33.206.807 pada versi orisinal dan 98.257 pada versi cover. Hal ini menandai bahwa kedua lagu tersebut dikenal luas serta memiliki banyak penggemar, pun demikian dengan versi covernya meski tidak ditonton dalam jumlah yang sama besar.

YouTube sebagai new media memegang peran penting untuk mengantar masyarakat pada nilai-nilai kapitalis. Seperti yang disebutkan oleh Hopkins sebagaimana dikutip oleh Swara (2014: 1-2) bahwa jaringan internet sebagai new media mengubah perilaku komunikasi masyarakat; salah satunya adalah kebutuhan informasi audio-visual yang dapat dipenuhi melalui media YouTube. Hal ini direlasikan dengan bagaimana musisi ternama membentuk identitasnya melalui karya musiknya yang diunggah pada kanal YouTube mereka. Sebagai musisi ternama, pendistribusian karya musik versi orisinal memiliki ruang yang jauh lebih luas dibandingkan dengan pendistribusian versi cover. Hal ini direlasikan dengan preferensi penonton pada media YouTube, di mana jumlah penonton serta pelanggan pada kanal YouTube musisi versi orisinal lebih banyak dibandingkan dengan cover creator. Dengan demikian, versi cover menandakan bahwa pembaruan musikal mampu mendatangkan nilai-nilai kapitalis beserta perubahan identitas di dalamnya.

Sebagai new media, YouTube memproduksi tanda (kebutuhan informasi audiovisual), menyebarkannya dan berakhir dengan mereproduksinya. Hal tersebut kemudian dihubungkan dengan fenomena cover version yang memiliki sistem berpola di dalamnya; seperti unsur-unsur kemudahan (mudah diakses, mudah ditirukan, mudah dikreasikan kembali) serta penghasilan yang dapat diperoleh berkontribusi meningkatkan jumlah cover creator pada situs YouTube. Adapun genre musik yang banyak mengalami pengcoveran ialah genre musik pop. Hal ini menandakan bahwasanya genre musik pop mudah mengalami perubahan dalam bentuk versi cover. Pemahaman ini berhubungan dengan genre musik pop sebagai bagian dari budaya populer yang mudah melebur dan cair dengan berbagai hal lain di luar dirinya. Unsur kemudahan ini direlasikan dengan peran kemajuan teknologi yang mudah diakses publik sebagai wujud kebutuhan primer atas informasi audio-visual melalui situs YouTube.

\section{Perubahan Identitas dalam Narasi Lirik Lagu, Format Lagu, Instrumentasi, dan Video Musik}

Greene (2014: 5) menyebutkan bahwa suatu versi cover memiliki ideologi yang baru dan berbeda pada segi kontekstual dan musikalnya jika dibandingkan dengan versi orisinalnya. Perubahan yang terjadi antara versi orisinal dan versi cover salah satunya meliputi perubahan pada lirik lagu, citra yang dibangun oleh kedua kategori musisi ini (orisinal dan cover) serta media publikasi yang digunakan oleh keduanya. Hardjana (2003: 35) menyebutkan bahwa musik tidak hanya dicitrakan melalui sosok, peran, instrument, dan juga bukan sekadar kesan dan pesan; melainkan keseluruhan substansi wacana hubungan antara musik itu sendiri dengan subjek pemusik selaku pencipta dan penyajinya. Dengan demikian, pada pembahasan ini diuraikan bagaimana narasi lagu dalam dua versi (orisinal dan cover) memunculkan isu perubahan identitas. Narasi 
tersebut meliputi narasi lirik lagu, format lagu, instrumen musik yang digunakan, video musik yang dikreasikan serta aspek pribadi sebagai bagian dari identitas kedua kategori musisi ini. Narasi tersebut dibahas lebih lanjut berikut ini.

\section{Akad: Payung Teduh dan Mas Paijo}

Lagu Akad diciptakan oleh Mohammad Istiqamah Djamad atau biasa dikenal Is yang saat itu masih menjadi vokalis band Payung Teduh hingga ia memutuskan untuk berpisah per 31 Desember 2017 (https://tirto.id/is-dan-payung-teduh-dari-akad-jadi-pegat-cz9K diakses pada 8 Mei 2018). Melalui penelusuran dalam situs YouTube, lagu Akad dengan genre pop-folk ini merupakan bagian dari album Ruang Tunggu yang dipublikasikan pada 4 September 2017 (https://www.youtube.com/watch?v=viW0M5R2BLo diakses pada 11 Mei 2018). Kemunculan lagu ini berdekatan dengan pemberitaan keluarnya Is sebagai vokalis, sehingga lagu $\mathrm{Akad}$ mendapat perhatian bertambah dari para penikmat musik. Hal ini terbukti dari banyaknya media online yang memberitakannya dengan beragam judul, seperti pada tirto.id (https://tirto.id/is-dan-payung-teduh-dari-akad-jadi-pegat-cz9K diakses pada $11 \mathrm{Mei}$ 2018) disebutkan "Is dan Payung Teduh: dari Akad jadi Pegat", kemudian pada kompas.com (https://entertainment.kompas.com/read/2017/09/11/190738910/5-fakta-di-balik-lagu-akadmilik-payung-teduh diakses pada 11 Mei 2018) dengan judul "5 Fakta di Balik Lagu Akad Milik Payung Teduh" kemudian pada brilio.net (https://www.brilio.net/selebritis/ini-curhat-vokalispayung-teduh-soal-maraknya-cover-lagu-akad-tak-izin-170928b.html diakses pada 11 Mei 2018) dengan judul "Ini Curhat Vokalis Payung Teduh Soal Maraknya Cover Lagu Akad Tanpa Izin" dan lain sebagainya.

Payung Teduh sebagai band indie mulai terbentuk pada tahun 2007 sebagai pemusik Teater Pagupon FIB UI (Fakultas Ilmu Pengetahuan Budaya Universitas Indonesia) yang dikenal puitis melalui lirik lagunya (https://www.kaskus.co.id/thread/000000000000000012562085/singgah-sejenak-di-bawah-quotpayungteduhquot-the-official-thread/ diakses pada 8 Mei 2018). Personel Payung Teduh saat itu terdiri dari Is pada vokal dan gitar, Comi pada kontrabas, Cito pada drum dan perkusi, serta Ivan pada gitalele (gitar-ukulele), trompet, dan backing vocals. Menurut artikel yang ditulis oleh Tim Redaksi KapanLagi.com (https://www.kapanlagi.com/payung-teduh/profil/ diakses pada 14 Mei 2018), Payung Teduh merilis album indie pertamanya dengan judul Payung Teduh pada tahun 2010, kemudian pada tahun 2012 lahir album kedua dengan judul Dunia Batas, dan album ketiga yang rilis pada tahun 2017 dengan judul Ruang Tunggu.

Lagu Akad merupakan bagian dari album ketiga Payung Teduh, menceritakan suatu kisah cinta. Hal ini serupa dengan judulnya, akad yang diartikan sebagai sebuah janji, direlasikan dengan janji sepasang kekasih, sebuah keluarga, janji antar teman dalam suatu kelompok hingga janji yang teringkari dan mendatangkan kesedihan. Narasi tersebut dideskripsikan melalui video musik dan lirik lagu yang mengisahkan tentang seseorang yang sedang jatuh cinta; berupa pengharapan, kecemasan akan perpisahan, hingga berlanjut ajakan untuk menikah pada sang kekasih.

Instrumen musik yang kuat terdengar dalam lagu ini ialah trompet, khususnya pada bagian intro, interlude, dan coda. Menurut Oxford Dictionary of Music (1985: 217 503) definisi intro (introduction) adalah permulaan dalam sebuah karya musik, definisi interlude adalah jeda antara dua bagian yang berbeda dalam karya musik kemudian 
definisi coda yaitu akhir dari serangkaian bagian yang tersusun dalam sebuah karya musik. Narasi instrumentasi yang dipaparkan ini dilanjutkan dengan uraian versi cover dari lagu Akad yang dikreasikan oleh Mas Paijo.

Pengcoveran lagu Akad oleh Mas Paijo menunjukkan perubahan genre yang semula pop menjadi keroncong. Hal ini terdengar melalui dominasi penggunaan instrumen musik cuk atau ukulele yang ditandai sebagai identitas genre musik keroncong (Thole, 2014: 1). Menurut Ganap, musik keroncong mendapat pengaruh budaya Jawa pada abad ke-20 yang kemudian melahirkan bentuk keroncong asli serta langgam Melayu dan Jawa (2006: 7).

Nuansa keroncong pada versi cover lagu Akad oleh Mas Paijo juga direlasikan dengan penggunaan atribut dalam budaya Jawa, seperti penggunaan kemeja batik serta blangkon oleh Mas Paijo dalam video musiknya dan penggunaan bahasa Jawa dalam lirik lagu versi cover tersebut. Beberapa unsur dari budaya Jawa yang digunakan oleh Mas Paijo mengindikasikan identitas yang diusung olehnya. Dengan demikian ditemukan adanya keterkaitan antara budaya Jawa dengan genre musik keroncong yang ditampilkan dalam lagu Akad versi cover Mas Paijo. Hal ini secara tidak langsung membangun identitas Mas Paijo sebagai cover creator sekaligus mengubah citra lagu pada versi orisinalnya.

Dalam kanal YouTube milik Mas Paijo diketahui bahwa ia tidak hanya menciptakan versi cover pada lagu-lagu pop Indonesia saja, melainkan juga pada lagulagu Barat, seperti Perfect dari Ed Sheeran, New Rules dari Dua Lipa, Havana dari Camila Cabello, dan lain sebagainya yang juga ia ubah ke dalam bahasa Jawa lengkap dengan penggunaan atribut budaya Jawa, yaitu kemeja batik dan blangkon dalam video musiknya (https://www.youtube.com/channel/UCiQNOegYeCp6rQchOZZG_xw/videos?sort=p\&view=0\&shelf_id=1di akses pada 11 Mei 2018). Hal ini mengindikasikan konsistensi serta kontinuitas Mas Paijo sebagai cover creator yang telah ia jalani sejak 21 Juli 2017 dengan total video covernya sekitar dua belas video. Hal ini juga menandakan adanya unsur subjektivitas cover creator dengan budaya Jawa.

Dalam tabel berikut ditunjukkan perubahan yang terjadi pada lagu Akad versi orisinal oleh Payung Teduh dan versi cover oleh Mas Paijo. 
Tabel I. Narasi Lirik Lagu, Instrumentasi, dan Video Musik

\begin{tabular}{|c|c|c|c|}
\hline No. & Perbedaan & $\begin{array}{l}\text { Versi Orisinal } \\
\text { (Payung Teduh) }\end{array}$ & $\begin{array}{l}\text { Versi Cover } \\
\text { (Mas Paijo) }\end{array}$ \\
\hline 1. & Lirik lagu & $\begin{array}{l}\text { Betapa bahagianya hatiku saat ku duduk } \\
\text { berdua denganmu. } \\
\text { Berjalan bersamamu, } \\
\text { menarilah denganku } \\
\text { Namun bila hari ini adalah yang terakhir } \\
\text { Namun ku tetap bahagia } \\
\text { Selalu ku syukuri } \\
\text { Begitulah adanya } \\
\text { Namun bila kau ingin sendiri } \\
\text { Cepat cepatlah sampaikan kepadaku } \\
\text { Agar ku tak berharap } \\
\text { Dan buat kau bersedih } \\
\text { Bila nanti saatnya tlah tiba } \\
\text { Ku ingin kau menjadi istriku } \\
\text { Berjalan bersamamu dalam terik dan } \\
\text { hujan } \\
\text { Berlarian ke sana kemari dan tertawa } \\
\text { Namun bila saat berpisah tlah tiba } \\
\text { Izinkanku menjaga dirimu } \\
\text { Berdua menikmati pelukan di ujung } \\
\text { waktu } \\
\text { Sudikah kau temani diriku? }\end{array}$ & $\begin{array}{l}\text { Jan bungaeh tenanan atiku } \\
\text { pas kowe njagong loronan mbe aku. } \\
\text { Mlaku bareng sliramu, } \\
\text { njoget bareng mbe aku } \\
\text { Nanging yen dinone iki dino seng } \\
\text { terakhir } \\
\text { Nanging ku tetep bahagia } \\
\text { Aku tansah syukuri } \\
\text { Koyo ngene anane } \\
\text { Nanging yen kowe pengen dhewekan } \\
\text { Cepet cepeto Dhek ngomongo marang } \\
\text { aku } \\
\text { Ben aku ora ngarep } \\
\text { Nggawe kowe nelongso } \\
\text { Nanging yen wektune uwes teko } \\
\text { Ku pengen kowe dadi bojoku } \\
\text { Mlaku bebarengan neng srengenge lan } \\
\text { udan } \\
\text { Mlayu mlayu mrono mrene karo ngguya } \\
\text { ngguyu } \\
\text { Nanging yen mengko sorene teko } \\
\text { Ijinken ku njogoni sliramu } \\
\text { Loronan ngrasake sikepan neng dowone } \\
\text { wektu } \\
\text { Gelem ra Dhek kowe dadi bojoku? }\end{array}$ \\
\hline 2. & $\begin{array}{l}\text { Instrumen } \\
\text { musik } \\
\text { yang } \\
\text { dominan } \\
\text { terdengar }\end{array}$ & $\begin{array}{l}\text { Trompet yang kuat terdengar pada } \\
\text { bagian intro, interlude, dan coda. }\end{array}$ & $\begin{array}{l}\text { Cak/Ukulele yang kuat terdengar dari } \\
\text { awal hingga akhir lagu. }\end{array}$ \\
\hline 3. & $\begin{array}{l}\text { Video } \\
\text { musik }\end{array}$ & $\begin{array}{l}\text { Dinarasikan terdapat seorang Bapak } \\
\text { yang berperan sebagai sopir sedang } \\
\text { mengendarai mobilnya. Dalam } \\
\text { perjalanannya ia bertemu dengan } \\
\text { sepasang kekasih muda, sebuah } \\
\text { keluarga yang terdiri dari Ayah, Ibu, } \\
\text { dan seorang anak laki-laki, seorang } \\
\text { perempuan single dengan raut wajah } \\
\text { bersedih dan sekelompok anak muda } \\
\text { yang terdiri dari satu perempuan dan } \\
\text { dua laki-laki yang menggunakan jasa } \\
\text { Bapak sopir tersebut. Di dalam mobil } \\
\text { ditampakkan ekspresi dari keempat } \\
\text { kelompok penumpang tadi yang juga } \\
\text { berinteraksi dengan Bapak sopir. } \\
\text { Kemunculan keempat kelompok } \\
\text { penumpang secara acak ini terkadang }\end{array}$ & $\begin{array}{l}\text { Dinarasikan terdapat tiga laki-laki muda } \\
\text { dalam sebuah studio musik dengan } \\
\text { posisi duduk pada kursi masing-masing. } \\
\text { Dalam video tersebut, Mas Paijo duduk } \\
\text { di posisi sentral; tengah agak depan. } \\
\text { Mas Paijo sebagai vokalis sekaligus } \\
\text { bermain ukulele dan dua lainnya } \\
\text { bermain keyboard serta gitar. Adapun } \\
\text { instrumen musik cajon terdengar dalam } \\
\text { versi cover ini, namun tidak } \\
\text { ditampakkan siapa yang memainkannya; } \\
\text { hanya berupa suara. Mas Paijo } \\
\text { mengenakan kemeja batik lengkap } \\
\text { dengan blangkonnya, sedangkan dua } \\
\text { pemusik pengiringnya mengenakan } \\
\text { kemeja polos. Dalam versi cover ini } \\
\text { masih menyisipkan suara dari instrumen }\end{array}$ \\
\hline
\end{tabular}




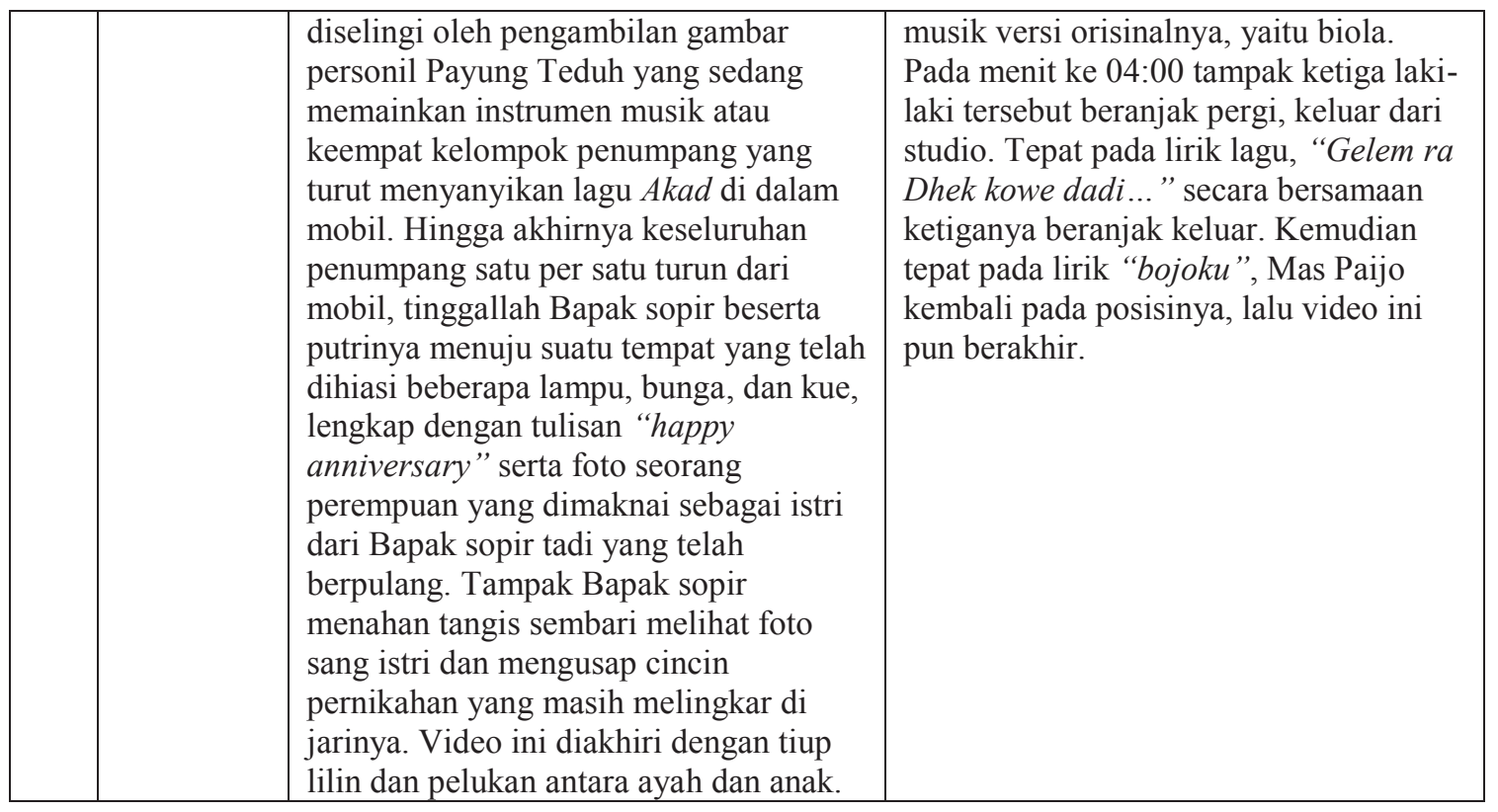

Analisis untuk poin pertama, yaitu identitas lagu Akad yang ditampilkan melalui lirik lagu tentang kisah percintaan, sebuah ikatan janji, seperti dalam kalimat "ku ingin kau menjadi istriku" dan "izinkanku menjaga dirimu" yang merepresentasikan makna dari akad itu sendiri. Kemudian identitas ini berubah secara kebahasaan, dari yang semula bahasa Indonesia menjadi bahasa Jawa. Perubahan bahasa ini tidak lantas mengubah makna lagu sebelumnya, seperti dalam kalimat "ku pengen kowe dadi bojoku" dan “ijinken ku njogoni sliramu”. Perubahan bahasa ini menuntun pada analisis poin kedua yaitu genre musik yang lekat dengan persoalan instrumen musik yang dominan terdengar. Pada versi orisinal lagu Akad yang bergenre pop-folk dengan instrumen musik yang dominan terdengar yaitu trompet kemudian berubah identitasnya pada versi cover yang bergenre keroncong dengan penggunaan ukulele sebagai instrumen musik yang dominan terdengar. Perubahan identitas yang dimunculkan melalui lirik lagu, genre musik, instrumentasi musik ini menuntun pada analisis poin ketiga, yaitu video musik. Pada video musik versi orisinal menampakkan nilai-nilai budaya populer dalam masyarakat, salah satunya ditunjukkan melalui kendaraan yang digunakan, pakaian yang digunakan, gawai yang digunakan, dan lain sebagainya. Hal ini kemudian berubah menjadi narasi yang memuat unsur-unsur budaya Jawa melalui penggunaan batik dan blangkon dalam video musik versi cover Mas Paijo. Dengan demikian, kedua versi tersebut membentuk wacana yang terkait dengan bagaimana musisi menampilkan identitas dirinya dalam ruang publik.

\section{Pamit: Tulus dan Sintesa Vocal Play}

Lagu Pamit yang diciptakan oleh Tulus dan Ari Renaldi (produser musik) ini merupakan bagian dari album Monokrom yang dirilis pada 3 Agustus 2016 (http://creativedisc.com/2016/07/album-baru-tulus-berjudul-monokrom-rilis-3-agustus-2016/ diakses pada 12 Mei 2018). Kemunculan lagu Pamit masih mendapat perhatian publik hingga kini, terlebih 
saat lagu ini digunakan sebagai musik pengiring pada kejuaraan European Figure Skating Championship 2018 di Moscow-Rusia pada 21 Januari silam. Suasana sendu dalam lagu Pamit yang digunakan berdurasi satu menit lebih empat puluh lima detik ini mengiringi liukan Dasa Grm-seorang peseluncur es dari Slovenia, yang diteruskan dengan lagu Eden Roc dari Ludovico Einaudi dan Human dari Christina Perri (https://kumparan.com/@kumparannews/saat-lagu-pamit-tulus-mengiringi-peserta-kejuaraan-ice-skatingeropa diakses pada 12 Mei 2018).

Tulus merupakan penyanyi solo laki-laki asal Bukittinggi-Sumatera Barat yang mengawali karirnya sejak tahun 2011. Kehadirannya dalam industri musik Indonesia disambut dengan banyak respons positif dari para penikmat musik; salah satunya Majalah Rolling Stone Indonesia yang memberikan Tulus penghargaan sebagai Rookie of The Year pada tahun 2013; selain itu, beberapa konser telah digelar oleh Tulus beserta tim produksi musiknya sejak awal karirnya, yaitu: An Introduction (2011), kemudian Beyond Sincere (2012), Konser Diorama (2013), Konser Gajah Bandung (2014), Konser Gajah Jakarta (2014), dan Konser Gajah Yogyakarta (2015) (https://www.situstulus.com/biografi/ diakses pada 12 Mei 2018).

Lagu Pamit memuat cerita tentang perpisahan dan kesedihan yang mendalam. Makna perpisahan dalam lagu ini tersirat melalui judulnya - Pamit - yang direlasikan dengan terputusnya hubungan sepasang kekasih karena perbedaan yang ada di antara keduanya, demikian pula yang tergambarkan pada lirik lagu serta video musiknya. Dalam video musik yang berdurasi empat menit lebih empat puluh sembilan detik ini, pendengar disuguhkan iringan musik orkestrasi di dalamnya; scoring musik dalam lagu Pamit ini dibawakan oleh The City of Prague Philharmonic Orchestra. Definisi scoring menurut Oxford Dictionary of Music (1985: 942) adalah proses dan seni mengorkestrasikan sebuah komposisi musik. Pada umumnya, alat-alat musik orkestra meliputi instrumen strings (cello, biola, contra bass), woodwind (flute, oboe, clarinet), brass (trumpet, trombone), dan percussion (timpani, bell tree, dan lain sebagainya) (Fu'adi, 2009: 1).

Sementara itu, versi cover lagu Pamit yang ditelaah dalam tulisan ini dikreasikan oleh Sintesa Vocal Play; sebuah grup musik akapela dari Yogyakarta yang terbentuk sejak tahun 2003; terdiri dari tujuh laki-laki berusia antara 24-28 tahun, yaitu: Kayyis, Fikri, Rois, Chandra, Bufe, Yusuf, dan Erwin; dengan pembagian suara dari tinggi ke rendah: tenor, baritone, dan bass (http://www.sintesavocalplay.com/ diakses pada 14 Mei 2018). Adapun definisi akapela menurut Oxford Dictionary of Music (1985: 4) ialah suatu paduan suara tanpa iringan instrumen musik yang biasa dinyanyikan di gereja dan dikenal sejak abad keenam belas. Hal ini direlasikan dengan persoalan antara akapela dengan gereja yang kemudian diadopsi oleh Islam dengan nasyid. Nasyid merupakan nyanyian dakwah islami yang pada umumnya dibawakan secara akapela kemudian kini berkembang dengan menggunakan instrumen musik. Pemahaman ini ditimbulkan sebab lagu-lagu yang banyak dicover oleh Sintesa Vocal Play ialah lagu-lagu bernuansa keagamaan. Salah satunya yaitu: Iman dari Ahmad Dhani, Tuhan dari Bimbo, Sepohon Kayu dari Ust. Jeffry Al Buchori, dan Kun Anta dari Humood Alkhuder (https://www.youtube.com/channel/UCsDrzNjBfjkyiicDskWp_mg/videos diakses pada 14 Mei 2018). 
Tabel II. Narasi Format Lagu, Instrumentasi dan Video Musik

\begin{tabular}{|c|c|c|c|}
\hline No. & Perbedaan & $\begin{array}{l}\text { Versi Orisinal } \\
\text { (Tulus) }\end{array}$ & $\begin{array}{l}\text { Versi Cover } \\
\text { (Sintesa Vocal Play featuring } \\
\text { Anandito) }\end{array}$ \\
\hline 1. & Format lagu & Orkestrasi & Akapela \\
\hline 2. & $\begin{array}{l}\text { Instrumen } \\
\text { musik yang } \\
\text { dominan } \\
\text { terdengar }\end{array}$ & $\begin{array}{l}\text { Piano dan instrumen string section, } \\
\text { meliputi: biola, violin, cello, dan } \\
\text { double bass. }\end{array}$ & $\begin{array}{l}\text { Hanya vokal dengan pembagian } \\
\text { delapan suara laki-laki (bersama } \\
\text { Anandito) }\end{array}$ \\
\hline 3. & Video musik & $\begin{array}{l}\text { Dinarasikan di suatu tempat di Praha, } \\
\text { Republik Ceko yang saat itu sedang } \\
\text { turun salju. Lalu lintas perkotaan } \\
\text { dipadati kendaraan dan pejalan kaki } \\
\text { serta jalanan yang bersalju. Tiap sisi } \\
\text { rumah menampakkan suasana sepi, } \\
\text { seperti jendela yang tirainya tertiup } \\
\text { angin dan selembar kertas yang } \\
\text { bergerak tertiup angin dengan segelas } \\
\text { air mineral di sebelahnya, di atas } \\
\text { meja. Suara yang melatarbelakangi } \\
\text { tiap bagian dalam video tersebut } \\
\text { meliputi bunyi kendaraan di jalan } \\
\text { raya, suara angina, dan suara air } \\
\text { mengalir. Pada menit ke satu, musik } \\
\text { mulai dimainkan bersama dengan } \\
\text { deru angin dan salju yang turun. } \\
\text { Setting tempat yang diambil berada di } \\
\text { luar rumah, di pinggir jalan, dan di } \\
\text { tengah jalan yang diambil dari atas. } \\
\text { Kemudian kembali masuk ke ruangan } \\
\text { dalam rumah dengan lagu yang telah } \\
\text { diputar. Pengambilan gambar } \\
\text { dilakukan secara acak, dari luar } \\
\text { ruangan, berpindah ke dalam ruangan } \\
\text { kemudian kembali ke luar, dan } \\
\text { seterusnya. Dalam video tersebut } \\
\text { tampak Tulus mengenakan coat } \\
\text { berwarna hitam di jalanan yang } \\
\text { bersalju sembari menyanyikan lagu } \\
\text { Pamit dengan raut wajah sendu. } \\
\text { Nampak pula burung merpati } \\
\text { berwarna hitam yang mengepakkan } \\
\text { sayapnya lalu terbang di menit kedua. } \\
\text { Warna yang mendominasi video } \\
\text { musik tersebut ialah hitam dan putih. } \\
\text { Setting waktunya dimulai dari pagi } \\
\text { hari hingga petang hari, yang ditandai } \\
\text { dengan hari semakin gelap dan } \\
\text { dinyalakannya lampu-lampu jalan. } \\
\text { musik ini. }\end{array}$ & $\begin{array}{l}\text { Dinarasikan di suatu tempat di } \\
\text { Yogyakarta (diketahui berdasarkan } \\
\text { salah satu sudut pengambilan } \\
\text { gambar di Masjid UGM dan di } \\
\text { Kampus UPN Veteran) yang saat } \\
\text { itu sedang turun hujan. Pada sebuah } \\
\text { ruangan tampak seorang laki-laki } \\
\text { (Anandito) duduk tertunduk dengan } \\
\text { secangkir teh di hadapannya. } \\
\text { Sesekali ia menatap keluar jendela } \\
\text { seolah sedang memikirkan sesuatu. } \\
\text { Kemudian setting tempat beralih ke } \\
\text { dalam masjid dan tampak Anandito } \\
\text { sedang membaca Al Qur'an. } \\
\text { Kemudian scene beralih ke dalam } \\
\text { ruangan dengan posisi Anandito } \\
\text { sedang menghubungi seseorang } \\
\text { dengan nama yang tertera di } \\
\text { handphonenya, "Sayangku". Pada } \\
\text { scene berikutnya seorang } \\
\text { perempuan mengangkat telepon } \\
\text { dari Anandito. Keduanya } \\
\text { membicarakan sesuatu dengan raut } \\
\text { muka sedih juga bingung yang } \\
\text { berlanjut pada scene berikutnya, } \\
\text { keduanya beradu argumen melalui } \\
\text { handphone masing-masing dengan } \\
\text { dua setting tempat yang berbeda. } \\
\text { Kemudian tampak Anandito } \\
\text { mengirim pesan singkat pada } \\
\text { kekasihnya dengan maksud } \\
\text { mengakhiri hubungan mereka } \\
\text { berdua, lalu ia sholat di dalam } \\
\text { masjid. Kisah dalam video ini } \\
\text { diakhiri ketika Anandito mengubah } \\
\text { nama panggilan kekasihnya dalam } \\
\text { kontak handphone, dari } \\
\text { "Sayangku" menjadi nama aslinya, } \\
\text { "Putri". Kemudian keduanya tidak } \\
\text { sengaja bertemu dan Anandito } \\
\text { tampak menolak bersalaman } \\
\text { dengan sang mantan kekasih. }\end{array}$ \\
\hline
\end{tabular}


Analisis untuk poin pertama yaitu identitas lagu Pamit yang dimunculkan melalui format lagu. Pada versi orisinal lagu Pamit dibawakan secara orkestrasi oleh The City of Prague Philharmonic Orchestra. Kemudian identitas ini berubah pada versi cover yang dibawakan secara akapela dengan pembagian delapan suara laki-laki. Analisis untuk poin kedua ditampilkan melalui instrumen musik; pada versi orisinal didominasi oleh string section sedangkan pada versi cover didominasi oleh vokal saja. Hal ini direlasikan dengan perubahan identitas yang memunculkan nilai baru pada karya musik versi orisinalnya, karena suatu format lagu mencerminkan bagaimana musisinya dikenal dalam ruang publik. Terakhir, analisis poin ketiga yang dimunculkan melalui video musik di mana keduanya sama-sama membangun cerita di dalamnya. Pada versi orisinal tampak gambaran cerita tentang kesendirian seseorang yang telah berpisah dengan kekasihnya, sedangkan pada versi cover ditampakkan bagaimana sepasang kekasih mengalami perdebatan hingga akhirnya memutuskan untuk berpisah. Dari pembacaan narasi versi orisinal dan versi cover ini tampak adanya perubahan identitas yang berhubungan dengan nilai kedua kategori musisi tersebut (orisinal dan cover); Tulus yang dikenal dengan lagulagunya yang puitis dan Sintesa Vocal Play yang dikenal dengan nuansa religiusitasnya.

\section{Kesimpulan}

Dari analisis ini dapat disimpulkan bahwa perubahan identitas musik pop dalam versi cover memunculkan beberapa pembahasan sebagai bentuk kontribusi cover terhadap versi orisinal. Pembahasan tersebut meliputi peran penting teknologi dalam memunculkan beragam karya versi cover yang direlasikan dengan selera musik dari para pendengar serta bagaimana musik beserta musisinya membentuk identitasnya masing-masing melalui narasi lirik lagu, format lagu, instrumentasi musik, video musik hingga unsur personalitas dari masing-masing musisi. Dalam hal ini, musik dipahami sebagai suatu penanda untuk mendeskripsikan dirinya atas identitas yang ia miliki. Dengan demikian, versi cover telah membangun narasi terhadap beragam identitas yang ditawarkan di dalamnya. Hal tersebut berhubungan dengan bentuk pembaruan musikal yang meliputi interpretasi, membuka ruang apresiasi sehingga menghasilkan standar musik yang baru terhadap versi orisinal. Gagasan ini menandakan bahwa versi cover merupakan suatu upaya pembaruan musikal yang dicermati dalam bentuk perubahan identitas. Pada akhirnya suatu karya musik yang baru dalam versi cover melanggengkan eksistensi versi orisinalnya.

\section{Kepustakaan}

Frith, S. (2004). Music and Identity. In S. Frith (Ed.), Popular Music: Critical Concepts in Media and Cultural Studies (Vol. IV). London and New York: Routldege.

Fu'adi. (2009). Mengenal Lebih Dekat Musik Orkestra. Harmonia, IX (2).

Ganap, V. (2006). Pengaruh Portugis pada Musik Keroncong. Harmonia, VII (2). 
Greene, D. (2014). The Rock Cover Song: Culture, History, Politics. Jefferson, North Carolina: McFarland \& Company, Inc., Publishers.

Gustina, S. (2010). Gaya Bernyanyi dengan Teknik Bel Canto: (Re) Konstruksi Subjektivitas Penyanyi Perempuan dalam Pertunjukan Musik. Resital, 11(2), 8795.

Hardjana, S. (2003). Corat-Coret Musik Kontemporer Dulu dan Kini. Jakarta: MSPI.

Kennedy, M. (Ed.) (1985) Oxford Dictionary of Music. Oxford: Oxford University Press.

Plasketes, G. (2010). Play it Again: Cover Songs in Popular Music. Surrey, England: Ashgate Publishing Ltd.

Svašek, M. (2012). Moving Subjects, Moving Objects: Transnationalism, Cultural Production, and Emotions. New York and Oxford: Berghahn Books.

Swara, E. B. (2014). YouTube sebagai New Media: Pengaruhnya terhadap Masyarakat Indonesia Menurut Pemikiran Jean Baudrillard. (Bachelor), Universitas Indonesia.

Thole, K. (2014). Cara Mudah Bermain Ukulele. Buletin Tjroeng: Gelegak Jiwa Nusantara - Buletin Musik Keroncong, 16.

Wallach, J. (2008). Modern Noise, Fluid Genres: Popular Music in Indonesia, 19972001. Madison: The University of Wisconsin Press.

Wolfe, B., Nicholson, Norfleet, Wallach. (2005). Popular Music. In E. Koskoff (Ed.), Music Cultures in the United States: An Introduction. London and New York: Routledge.

Yangni, S. (2016). Jauh (Dekat), Yang Misterius Sekaligus Intim. Mata Jendela, XI.

\section{Webtografi}

Adam. (2012). Singgah Sejenak di Bawah "Payung Teduh". Dalam Kaskus Online: Macropedia Didapat dari: (https://www.kaskus.co.id/thread/000000000000000012562085/singgah-sejenakdi-bawah-quotpayung-teduhquot-the-official-thread/

Edinger, E. (2017). The Five Ways YouTubers Make Money. Dalam BBC Online:

Macropedia Didapat dari: http://www.bbc.co.uk/newsbeat/article/42395224/evanedinger-the-five-ways-youtubers-make-money

Editorial. (2017). Profil Payung Teduh. Dalam KapanLagi.com: Macropedia Didapat dari: https://www.kapanlagi.com/payung-teduh/profil/

Editorial. (2018). Saat Lagu 'Pamit' Tulus Mengiringi Peserta Kejuaraan Ice Skating Eropa. Dalam Kumparan News Online: Macropedia Didapat dari: https://kumparan.com/@kumparannews/saat-lagu-pamit-tulus-mengiringipeserta-kejuaraan-ice-skating-eropa

Faisal, M. (2017). Is dan Payung Teduh: dari Akad Jadi Pegat. Dalam tirto.id: Macropedia Didapat dari https://tirto.id/is-dan-payung-teduh-dari-akad-jadipegat-cz9K

IFPI. (2016). Global Recorded Music Sales Totalled US \$15.7 billion in 2016. Dalam Global Statistics IFPI: Macropedia Didapat dari: http://www.ifpi.org/globalstatistics.php

Kompas, Litbang. (2016). Layar jajak - Industri Musik Redup oleh Digital. Dalam Kompas Online: Macropedia Didapat dari: https://muda.kompas.id/2016/01/06/layar-jajak-industri-musik-redup-oleh-digital/

Pangerang, A. (2017). 5 Fakta di Balik Lagu Akad Milik Payung Teduh. Dalam Kompas Online: Macropedia Didapat dari: 
https://entertainment.kompas.com/read/2017/09/11/190738910/5-fakta-di-baliklagu-akad-milik-payung-teduh

Payung Teduh. (2017). Payung Teduh - Akad (Official Music Video). Dalam Kanal Payung Teduh Official: Macropedia Didapat dari: https://www.youtube.com/watch?v=viW0M5R2BLo

Rizky, A. (2018). Stats. Dalam Paijo Channel: Macropedia Didapat dari: https://www.youtube.com/channel/UCiQNOegYeCp6rQchOZZG_xw/about

Rumangun, W. (2017). Ini Curhat Vokalis Payung Teduh Soal Maraknya Cover Lagu Akad Tak Izin. Dalam Brilio Online: Macropedia Didapat dari: https://www.brilio.net/selebritis/ini-curhat-vokalis-payung-teduh-soal-maraknyacover-lagu-akad-tak-izin-170928b.html

Sintesa. (2015). Biografi. Dalam Situs Sintesa Vocal Play Online: Macropedia Didapat dari: http://www.sintesavocalplay.com/

Tulus. (2010). Biografi. Dalam Situs Tulus: Macropedia Didapat dari: https://www.situstulus.com/biografi/

Tulus. (2016). Press Release: "Pamit". Dalam Berita Situs Tulus Online: Macropedia Didapat dari: https://www.situstulus.com/press-release-pamit/

Tulus. (2016). Tulus - Pamit (Official Music Video). Dalam Kanal Musik Tulus: Macropedia Didapat dari: https://www.youtube.com/watch?v=G2-ZC9NpDBg

Urgo, J. (2008). All About Social Blade. Dalam Social Blade Online: Macropedia Didapat dari: https://socialblade.com/info

Verdy. (2016). Album Baru Tulus Berjudul Monokrom Rilis 3 Agustus 2016. Dalam Music Weblog Online: Macropedia Didapat dari:

http://creativedisc.com/2016/07/album-baru-tulus-berjudul-monokrom-rilis-3agustus-2016/ 